\title{
FORMULATION AND EVALUATION OF RACECADOTRIL MUCOADHESIVE MICROSPHERES
}

\section{KANCHAN JAMKAR ${ }^{1}$, SWATI MUTHA ${ }^{1}$, SHARVAREE HARDIKAR ${ }^{2}$, NIKHIL KUMBHAR ${ }^{1}$}

${ }^{1}$ Department of Pharmaceutics, SGRS College of Pharmacy, Saswad Pune, ${ }^{2}$ Department of Pharmaceutics, Allana College of Pharmacy, Pune

Email: swati.mutha@rediffmail.com

Received: 16 Oct 2019, Revised and Accepted: 20 Dec 2019

\section{ABSTRACT}

Objective: To develop and evaluate the mucoadhesive microsphere using combinations of natural polymers chitosan and xanthan gum for sustained release.

Methods: In the present work mucoadhesive microspheres were prepared by using natural polymers like chitosan and xanthan gum by using the emulsion chemical cross-linking method. Chemical cross-linking was done by using glutaraldehyde. The $2^{2}$ factorial design was employed to show the effect of cross-linking agent and processing factor-like stirring and speed. Prepared microspheres were evaluated for their particle size, surface morphology, drug entrapment efficiency, in vitro drug release, swelling index, and mucoadhesive strength.

Results: The size of microspheres of factorial batches were in the range of 26-46 $\mu \mathrm{m}$. The swelling index was showed in the range of 1.51-1.66 percentage. The equation of multiple regression revealed that there was significant interaction among factors. The glutaraldehyde concentration had a positive effect on \% entrapment efficiency, \% cumulative drug release and \% mucoadhesion. Stirring speed showed a negative impact on $\%$ entrapment efficiency, \% cumulative drug release and \% mucoadhesion. The interactive effect of glutaraldehyde concentration and the stirring speed was found to be positive for \% entrapment efficiency and \% cumulative drug release. In vitro drug release study of optimized formulation F2 show $96 \%$ of drug release with $6 \mathrm{~h}$ indicating sustained release behavior with diffusion mechanism. The SEM image of the optimized batch was spherical with a porous surface.

Conclusion: The results obtained in this research work indicated that a promising potential of chitosan and xanthan gum combination for the preparation of the mucoadhesive microsphere of Racecadotril.

Keywords: Chitosan, Xanthan gum, Racecadotril, Mucoadhesive microsphere, Natural polymer

(C) 2020 The Authors. Published by Innovare Academic Sciences Pvt Ltd. This is an open-access article under the CC BY license (http://creativecommons.org/licenses/by/4.0/A DOI: http://dx.doi.org/10.22159/ijpps.2020v12i2.36060. Journal homepage: https://innovareacademics.in/journals/index.php/ijpps

\section{INTRODUCTION}

The concept of multiple unit dosage forms was initially introduced in the early nineteen-fifties. Multiparticulate subunit, typically consisting of thousands of spherical with 0.005-2.00 mm. Recent trends showed that the multiparticulate drug delivery system is suitable for achieving the controlled release or prolong release formulations with no risks of dose dumping. Thus multiparticulate drug delivery system provides incredible opportunities for designing controlled release formulations [1-2]

Mucoadhesion is the topic of current interest in the design of the drug delivery system to prolong the residence time of the dosage form. Mucoadhesive Microsphere has advantageous like efficient absorption and enhanced bioavailability of the drug due to the high surface of volume ratio, much more contact with the mucous layer [3-5]. The mucoadhesive system adheres to the mucus. This adhesion is a result of electrostatic and $\mathrm{H}$-bond formation at the mucus-polymer boundary. The bond formation is prevented by the acidic environment and thick mucus present in the stomach, to overcome this problem cationic polymer chitosan is used which is known to bind well to GI track mucus and act as a penetration enhancer. Racecadotril is a thiorphan metabolite derivative, an enkephalinase inhibitor, which has antisecretory activity [6, 7]. It is active on $\mathrm{v}$-cholera bacteria in the gut by inhibiting adenylate cyclase. Racecadotril is approved for secretory diarrhea. It is also good for bacterial diarrhea and gonorrhea. Racecadotril is rapidly absorbed from the gastrointestinal tract. This drug has a repetitive dose schedule (100 to $300 \mathrm{mg}$ thrice daily up to $7 \mathrm{~d}$ in continue treatment), short biological half-life $(3 \mathrm{~h})$ and reduced bioavailability (30-40\%).

Thus, racecadotril is a candidate for the development of a gastroretentive drug delivery system. Due to mucoadhesion it may release drugs for a longer period and may increases bioavailability.
Racecadotril is very slightly soluble in water and hence only 30-40 $\%$ of the orally administered drug is absorbed. To enhance the extent of absorption, reduce dose, minimize the side effect of racecadotril, it needs to develop a gastroretentive drug delivery system i.e. Racecadotril in the form of mucoadhesive microsphere using combinations of natural polymers chitosan and xanthan gum for sustained release [8-10]

\section{MATERIALS AND METHODS}

Racecadotril was obtained as a gift sample from Cadila Healthcare Limited (Ahmadabad), India. xanthan gum, dioctyl sodium sulphosuccinate, and chitosan were obtained from S. K. enterprises Pune, Maharashtra. Heavy and light liquid paraffin, glutaraldehyde was obtained from research lab Mumbai. Maharashtra. All other chemicals and reagents used in the study were analytical grade.

\section{Analytical method}

Racecadotril was analyzed for percent entrapment efficiency (EE \%), percent cumulative drug release (\% CDR), and percent mucoadhesion by UV spectrophotometer (Shimadzu-1800, Japan) in $0.1 \mathrm{~N} \mathrm{HCl}$ by generating a standard curve for the range from 10 to 50 $\mu \mathrm{g} / \mathrm{ml}$ at $232 \mathrm{~nm}$

\section{Preparation of microspheres}

The mucoadhesive microsphere of racecadotril was prepared using the emulsification chemical cross-linking method. A 1 ml quantity of glacial acetic acid solution was dissolved in $100 \mathrm{ml}$ of distilled water it gives $1 \% \mathrm{~V} / \mathrm{V}$ solution of acetic acid. Chitosan was dissolved in $1 \%$ $\mathrm{V} / \mathrm{V}$ aqueous acetic acid solution and Xanthan gum added in the water. The drug was added to a polymer solution. The resultant mixture was extruded through a syringe in liquid paraffin (heavy and light 1:1 ratio) containing dioctyl sodium sulphosuccinate and stirring was performed using magnetic stirrer after $10 \mathrm{~min}$ 
glutaraldehyde ( $25 \%$ aqueous solution) was added and stirring was continued for $3 \mathrm{~h}$, microspheres thus obtained were filtered washed several times with petroleum ether to remove traces of oil. They were finally washed with water to remove an excess of glutaraldehyde and dried at room temperature [11-14].

The factorial formulations of racecadotril various microspheres formulations were mentioned in table 2 .

\section{Experimental design}

A 22 factorial design was utilized in the present study. Several studies revealed that the concentration of glutaraldehyde and stirring speed plays a major role in \% entrapment efficiency, \% cumulative drug release and \% mucoadhesion. The glutaraldehyde concentration and stirring speed were selected as independent variables. The \% entrapment efficiency, \% cumulative drug release, and \% mucoadhesion selected as dependent variables. Minitab 17 trial version was used for the generation and evaluation for the statistical experimental design. An ANOVA test was performed to evaluate the level of significance of the tested factors on the selected responses as well as the interaction between these factors. The application of regression analysis is important to check that our independent variable has a significant effect on our response or not. Surface response plots were also presented to graphically represent the effect of the independent variables on the \% entrapment efficiency, \% cumulative drug release and \% mucoadhesion.

Table 1: Variable levels in coded form

\begin{tabular}{lll}
\hline Variable & Low (-1) & High (+1) \\
\hline X1= Stirring speed (rpm) & 600 & 700 \\
X2= Concentration of glutaraldehyde & $2 \%$ & $3 \%$ \\
\hline
\end{tabular}

Table 2: Factorial formulations of mucoadhesive microspheres of racecadotril

\begin{tabular}{llll}
\hline Ingredients & Formulation & & \\
\cline { 2 - 4 } & F1 & F2 & F3 \\
\hline Racecadotril (mg) & 100 & 100 & 100 \\
Chitosan (mg) & 200 & 200 & 200 \\
Xanthan gum (mg) & 50 & 50 & 50 \\
Glutaraldehyde (ml) & 2 & 3 & 50 \\
Stirring speed (rpm) & 600 & 600 & 2 \\
1 \% Acetic acid (ml) & 25 & 25 & 700 \\
Distilled Water (ml) & 5 & 5 & 25 \\
\hline
\end{tabular}

\section{Particle size analysis}

The particle size of each formulation was determined by using Digital microscopy (Motic, Mumbai, India) method. Approximately 50 microspheres were counted for particle size using a calibrated digital electron microscope under $10 \mathrm{x}$.

\section{Swelling index}

A pre-weighed amount (100 mg) of microspheres was placed in acidic buffer $\mathrm{pH} 1.2$ and allowed to swell up to constant weight. The microspheres were removed and blotted with filter paper, and their changes in weight were measured [4]. The degree of swelling was then calculated from the following formula:

$$
\alpha=\frac{\mathrm{Wg}-\mathrm{Wo}}{\mathrm{Wo}} \times 100
$$

Where Wo is the initial weight of microspheres and Wg is the weight after swelling.

\section{Entrapment efficiency}

Microspheres were filled in the $5 \mathrm{ml}$ Centrifuge tube containing methanol. Perfectly sealed the cap of the tube. Placed the centrifuge on a firm level surface. The solution was filtered and the filtrate was diluted suitably and absorbance of the solution was recorded using a UV spectrophotometer at $232 \mathrm{~nm}$ and the value obtained used to determine the $\% \mathrm{EE}$ of drug content [15].

$$
\text { Entrapment efficiency }=\frac{\text { actual amount of drug }}{\text { therotical amount of drug }} \times 100
$$

\section{In vitro wash-off test (Mucoadhesive strength)}

The mucoadhesive properties of the microspheres were evaluated by the in vitro wash-off test. A $2 \times 2 \mathrm{~cm}$ piece of Goat stomach mucosa was tied onto a glass slide $(3 \times 1$ inch) using thread. Microspheres were spread $(-50)$ onto the wet, rinsed, tissue specimen, and the prepared slide was hung onto one of the groves of a USP tablet disintegrating test apparatus. The disintegrating test apparatus was operated such that the tissue specimen was given regular up and down movements in a beaker containing the acidic buffer $\mathrm{pH} 1.2$. At the end of $1 \mathrm{~h}$, the number of microspheres still adhering to the tissue was counted [17].

$$
\% \text { mucoadhesion }=\frac{\text { weight } \text { of adhering microsphere }}{\text { weight of microsphere }} \times 100
$$

\section{In vitro dissolution studies}

In vitro dissolution of the formulation was studied by taking the formulations equivalent to $100 \mathrm{mg}$ of a drug in $0.1 \mathrm{~N}$ HCL medium using the rotating paddle method at $37^{\circ} \mathrm{C} \pm 0.5{ }^{\circ} \mathrm{C}$ and at $100 \mathrm{rpm}$ using $900 \mathrm{ml} 0.1 \mathrm{~N}$ HCL dissolution media. Microsphere placed in dissolution media. At a suitable time interval, the $5 \mathrm{ml}$ sample was withdrawn from the dissolution apparatus and the sample was replaced with fresh $0.1 \mathrm{~N}$ HCL. and analyzed at a particular wavelength of $232 \mathrm{~nm}$ by UV Spectrophotometer. Further, the exact mechanism of drug release from the microsphere was calculated by curve fitting release data. Different release kinetic models such as zero-order, first-order, Higuchi and the Korsmeyer-Peppas equation were checked. The date of release kinetics were calculated.

\section{FTIR spectroscopy}

The FT-IR spectrum of Racecadotril was recorded as potassium bromide (Kbr) powder at a resolution of $4000-40 \mathrm{~cm}^{-1}$ for its authentication and to study principle peaks using FT-IR spectrophotometer (FT-IR 8400S, Shimadzu).

\section{Morphology of microspheres}

The surface morphology and shape of the Racecadotril microspheres were determined by scanning electron microscopy (SEM).

\section{Differential scanning calorimetry analysis (DSC)}

The thermograph of the Racecadotril was studied on a Mettler Toledo India Pvt. Ltd (Model DSC Star1). An empty aluminum pan was used as a reference. DSC measurements were performed at a heating rate of $10{ }^{\circ} \mathrm{C} / \mathrm{min}$ from 30 to $300{ }^{\circ} \mathrm{C}$ using an aluminum sealed pan. During the measurement, the sample was purged with nitrogen gas. 


\section{Release kinetic studies}

The rate and the mechanism of release of Racecadotril from the prepared mucoadhesive microspheres were analyzed by fitting the dissolution data into various kinetic models like zero order; first order, Korsmeyer Peppas, Higuchi's model.

\section{Stability study}

The stability of pharmaceutical products may be defined as the capability of a particular formulation, to remain within its physicalchemical microbiological therapeutic and toxicological specifications. The optimized formulation was filled into hard gelatin capsules (size $0)$. These capsules were packed in screw-capped bottles were kept in the humidity chamber maintained at $40 \pm 0.5{ }^{\circ} \mathrm{C}$ and $75 \pm 5 \% \mathrm{RH}$ for 3 mo. At the end of studies, Sample was analyzed for organoleptic properties, \% Entrapment Efficiency and \% Cumulative drug release, and \% Mucoadhesion.

\section{RESULTS}

Characterization of drug and excipients

\section{FTIR spectroscopy}

The IR spectra did not show any significant difference from those obtained for their physical mixture. These results indicated that the above polymer can be used without any interaction for the preparation of the Mucoadhesive Microsphere of Racecadotril. Following fig. shows the IR spectra of racecadotril and physical mixture (1:1) of Chitosan, Xanthan gum, and guar gum.

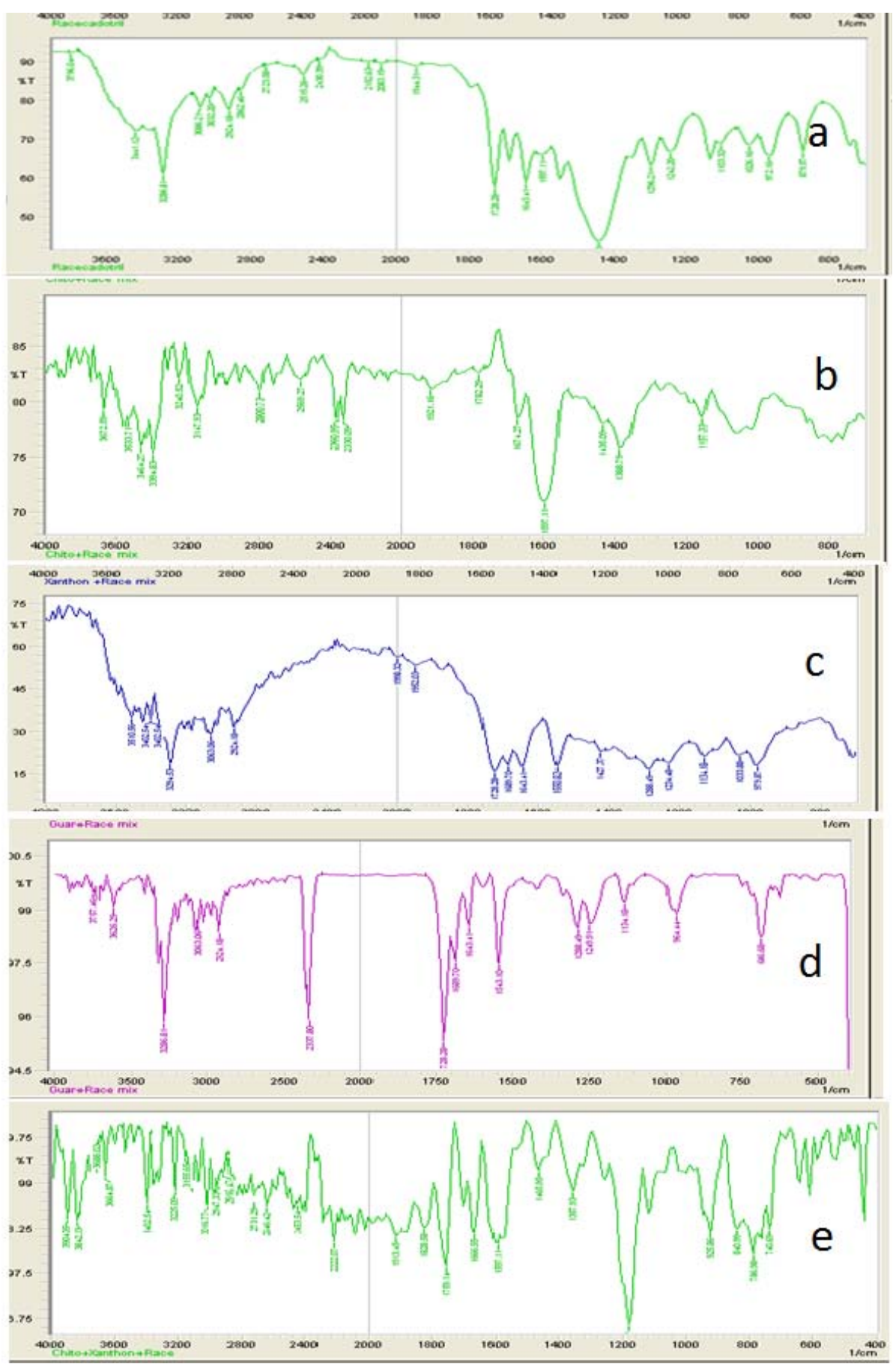

Fig. 1: FTIR spectra of (a) Racecadotril. (b) Racecadotril+Chitosan (c) Racecadotril+Xanthan gum (d) Racecadotril+Guar gum (e) Racecadotril+Chitosan+Xanthan 


\section{Differential scanning calorimetry analysis (DSC)}

DSC thermograph of a given sample of Racecadotril is shown in fig.
2. The thermogram showed the Endothermic peak at $85.63^{\circ} \mathrm{C}$ which is near to the actual melting point of the Racecadotril, from this it confirmed that the received gift sample of a drug is of Racecadotril.

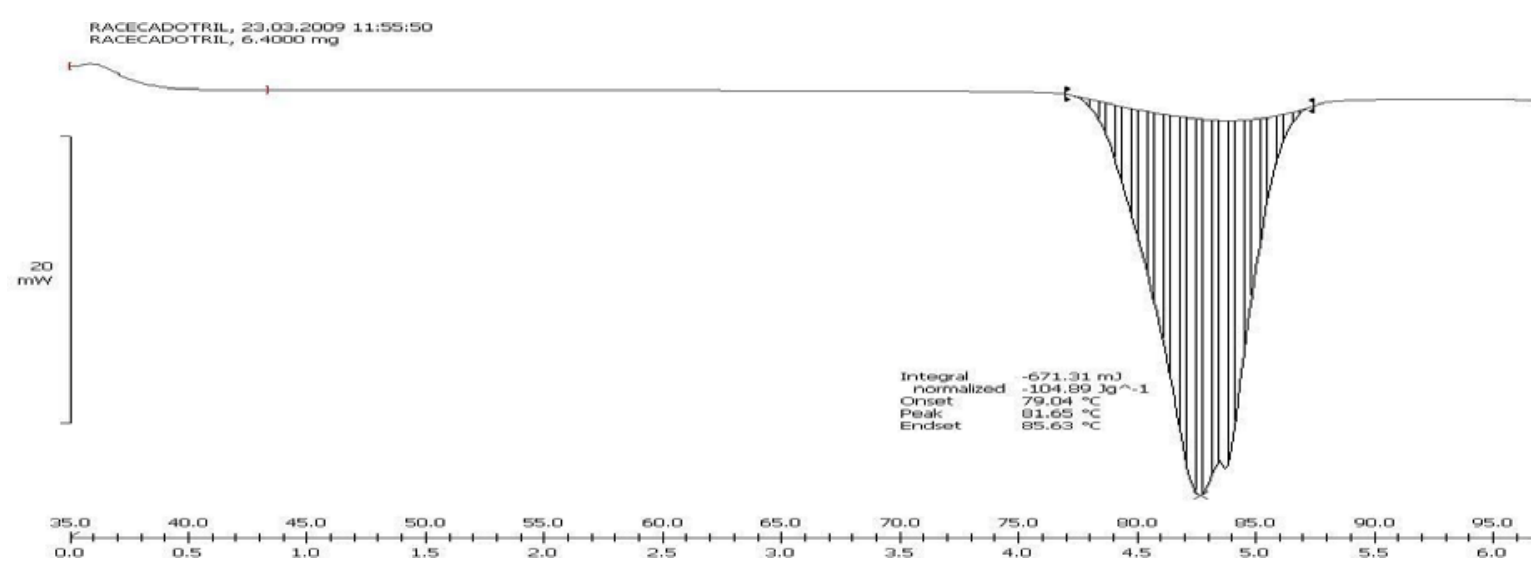

Fig. 2: DSC thermogram of racecadotril

Table 3: Characterization of mucoadhesive microsphere of racecadotril in factorial batches

\begin{tabular}{lllll}
\hline Formulation & $\begin{array}{l}* \text { Particle size }[\boldsymbol{\mu m}] \\
\text { (Under 10x) }\end{array}$ & $*$ Swelling index & $* \%$ Encapsulation efficiency & $\begin{array}{l}* \text { In vitro wash-off test }(\% M u c o a d h e s i o n) \\
\text { after } \mathbf{1} \text { h }\end{array}$ \\
\hline F1 & $46 \pm 0.32$ & 1.66 & $65.07 \pm 1.021$ & $69.3 \pm 3.42$ \\
F2 & $28 \pm 0.12$ & 1.42 & $67.42 \pm 1.032$ & $90.2 \pm 3.51$ \\
F3 & $38 \pm 0.35$ & 1.72 & $49.42 \pm 1.347$ & $78.5 \pm 4.26$ \\
F4 & $26 \pm 0.54$ & 1.51 & $58.52 \pm 1.031$ & $77.9 \pm 3.51$ \\
\hline
\end{tabular}

(*Represents mean $\mathrm{n}=3, \pm$ SD: standard deviations)

\section{Characterization of mucoadhesive microsphere of Racecadotril in factorial batches}

All results were summarized in table 3 .

\section{Analysis of factorial design}

The preliminary formulation screening data was utilized for defining design space in 22 full factorial designs shown in table 1 for an optimization study. The percent entrapment efficiency, Cumulative drug release, and \% mucoadhesion were selected as response parameters, as they play a major role in providing the efficacy of the formulation. The ANOVA study of the model as shown in table 4 for percent entrapment efficiency as a response, indicated that the model is significant and all the independent variables, as well as interaction factors, are found to have a significant effect on the response $(\mathrm{P} \leq 0.005)$.

Table 4: Results of ANOVA for response parameter

\begin{tabular}{llll}
\hline P Values of various response & & & \\
\hline Source & \% EE & \% CDR & \% Mucoadhesion \\
\hline Model & 0.001 & 0.001 & 0.001 \\
Linear & 0.001 & 0.0001 & 0.001 \\
S-Stirring speed & 0.001 & 0.001 & 0.001 \\
C-Conc of glutaraldehyde & 0.001 & 0.001 & 0.0001 \\
2-way interaction & 0.001 & 0.001 & 0.000 \\
$S^{*}$ C & 0.001 & 0.001 & 0.001 \\
\hline
\end{tabular}

The final regression model equation obtained was expressed in equation 1:

\section{\% Entrapment Efficiency = 60.1725-2.91500 S+6.18500 C+1.63750 S*C}

Where it can be noticed that all the main factors have a positive influence on \% EE. Where C is the concentration of glutaraldehyde and $S$ is the stirring speed. The interaction effect also significant.

Percentage entrapment efficiency was found to increase with an increased in glutaraldehyde Concentration and stirring speed. The formulation F2 showed the highest entrapment efficiency (67.42 \pm 1.032 ). The surface plot (fig. 3 ) showed a similar significant effect of stirring speed and glutaraldehyde concentration on $\%$ entrapment efficiency.

\section{$\%$ Cumulative drug release}

The in vitro release of all factorial batches were showed on the mucoadhesive microsphere (fig. 4). The drug release was studied for $6 \mathrm{~h}$. The Model terms for response \% cumulative drug release were found to be significant with $P$ value $<(p<0.005)$. As per ANOVA, all the factors found to be significant. The rate of drug release was found gradually increased by increasing the concentration of glutaraldehyde and decreased with an increase in stirring speed as shown in fig. 5 of the surface plot. The final regression model equation obtained was expressed in equation 2:

$\%$ Cumulative drug release $=86.9900-4.2125 \mathrm{~S}+5.6650 \mathrm{C}+0.4025$ $\mathrm{S}^{*} \mathrm{C}$ 


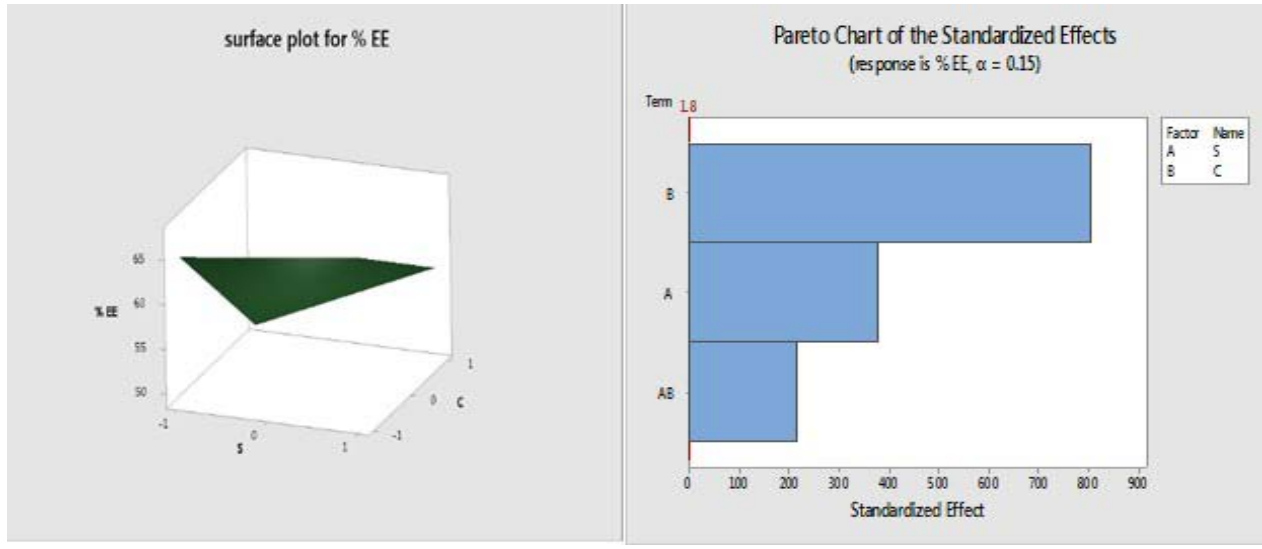

Fig. 3: Surface plot and pare to chart of $\%$ entrapment efficiency

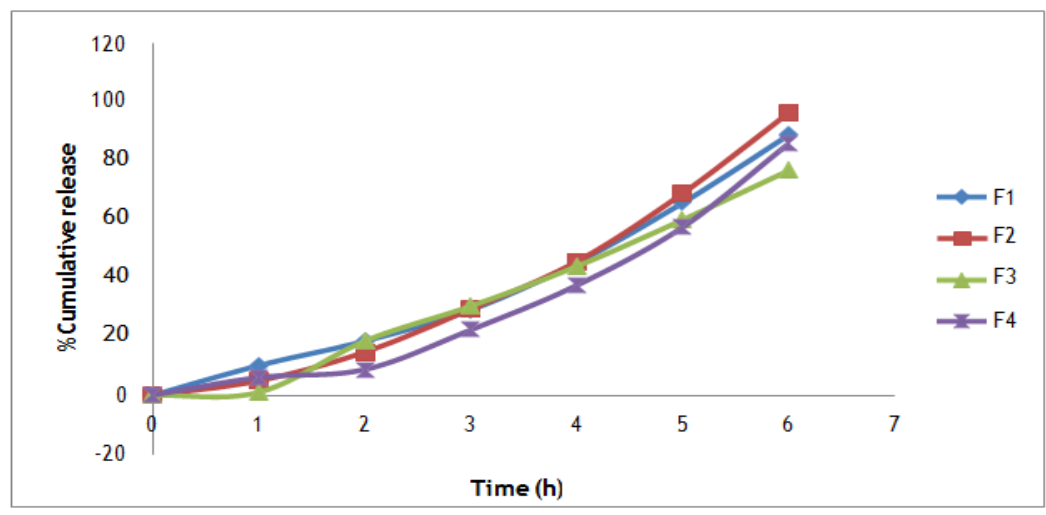

Fig. 4: In vitro drug release profile of F1, F2, F3 and F4 in $0.1 \mathrm{~N} \mathrm{HCl}$

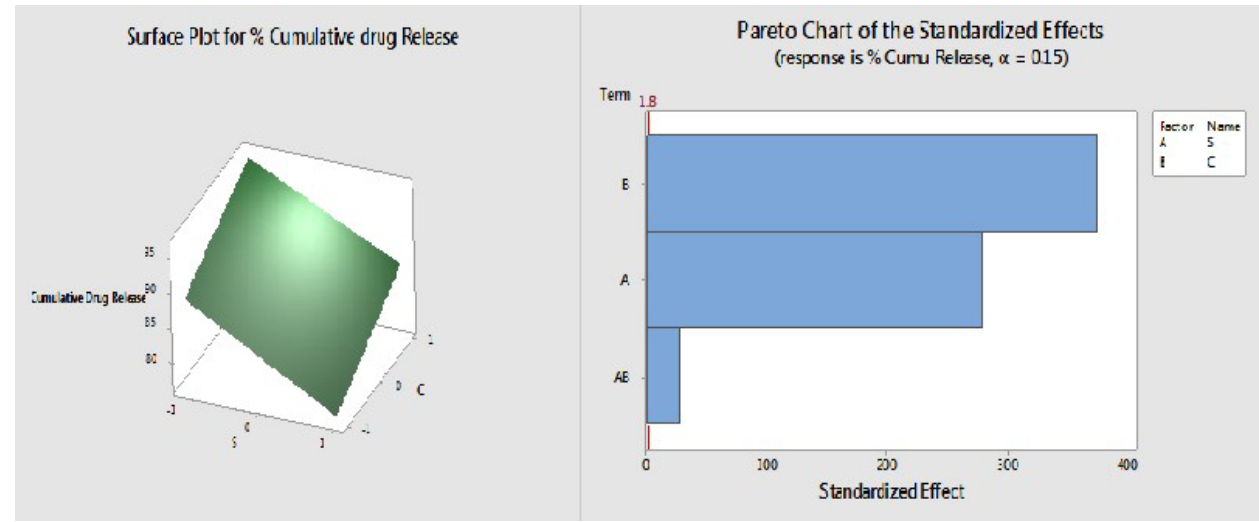

Fig. 5: Surface plot and pare to chart of $\%$ cumulative drug release

Further, in vitro release data were subjected to the curve fitting analysis to know the complex mechanism behind the drug release. In the case of the majority of formulations, the $\mathrm{R} 2$ values were much higher for the Higuchi model and Korsmeyer-Peppas model $\mathrm{n}$ value near 0.5 (table 5) indicating the drug release from the formulation followed diffusion kinetics.

Table 5: Data for study of release mechanism by curve fitting analysis

\begin{tabular}{llllll}
\hline Formulations & Zero-order & First-order & Higuchi & Korsmeyer's-Peppas & Hixoncrowel model \\
\cline { 2 - 5 } & R2 & R2 & R2 & R2 & 0.9065 \\
F1 & 0.9794 & 0.9271 & 0.9921 & 0.9813 & 0.9036 \\
F2 & 0.9644 & 0.9282 & 0.9932 & 0.9821 & 0.9060 \\
F3 & 0.9761 & 0.9295 & 0.9982 & 0.9885 & 0.9473 \\
F4 & 0.8979 & 0.9521 & 0.9355 & 0.9880 & \\
\hline
\end{tabular}

Where $\mathrm{R}^{2}=$ Correlation for the Korsmeyers-Peppas, zero-order, Higuchi models, First-order and the Hixon-Crowell model 


\section{$\%$ Mucoadhesion}

Pareto chart (fig. 6) showed a comparison between relative magnitude and the statistical significance of both main and interaction effects. The above result conveyed that stirring speed plays an important role in the mucoadhesive property of the racecadotril microspheres. ANOVA table Values of Prob $>\mathrm{P}$ less than 0.005 indicates the model term is significant. In this case, all the factors found to be significant. The study of in vitro mucoadhesion revealed that all the batches of prepared microsphere had good $\%$ mucoadhesion properties ranging from $69.3 \pm 3.42$ to $90.2 \pm 3.51 \%$. It was investigating that an increased in glutaraldehyde concentration increased mucoadhesion strength. The formulation F2 showed the highest mucoadhesive property $(90.2 \pm 3.51)$. These studies suggest that the spherical matrix of the microsphere can interact with many substrates on the surface of the stomach, and adhere to mucosa more strongly. The surface plot (fig. 6) showed the significant effect of an interactive factor on $\%$ mucoadhesion. It was observed that a decrease in stirring speed with a high level of glutaraldehyde concentration gave $\%$ Mucoadhesion value.

The final regression model equation obtained was expressed in equation 3:

$\%$ Mucoadhesion $=39.6900-0.4025 \mathrm{~S}+5.1600 \mathrm{C}-1.5425 \mathrm{~S} * \mathrm{C}$

\section{Stability study}

The Short term accelerated stability data obtained for optimized formulation revealed that organoleptic characteristics, $\%$ entrapment efficiency and \% cumulative drug release, mucoadhesion, and surface Morphology were within an acceptable limit. Thus the formulation can be said to be stable.

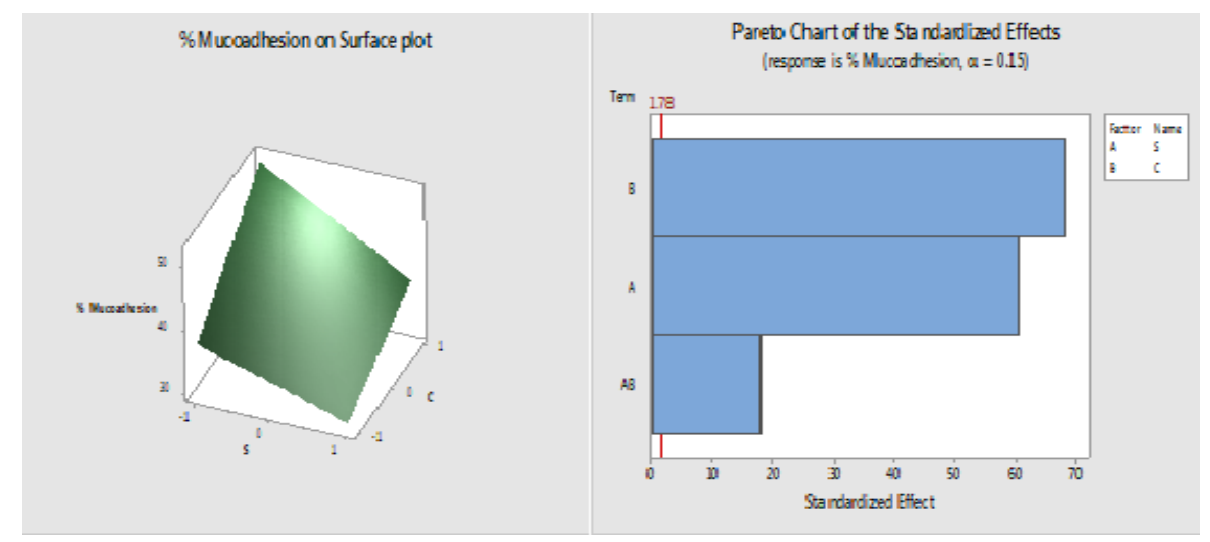

Fig. 6: Surface plot and pareto chart of $\%$ mucoadhesion

Table 6: Stability study of optimized mucoadhesive microsphere of Racecadotril formulation

\begin{tabular}{lll}
\hline Initial & Appearance & Yellowish-white \\
& \% Entrapment Efficiency & $67.65 \%$ \\
& \% Cumulative drug release & $96.43 \%$ \\
& \% Mucoadhesion & $90 \%$ \\
After 3 mo & Appearance & Yellowish-white \\
& \% Entrapment Efficiency & $66.38 \%$ \\
& \% Cumulative drug release & $95.36 \%$ \\
\hline
\end{tabular}

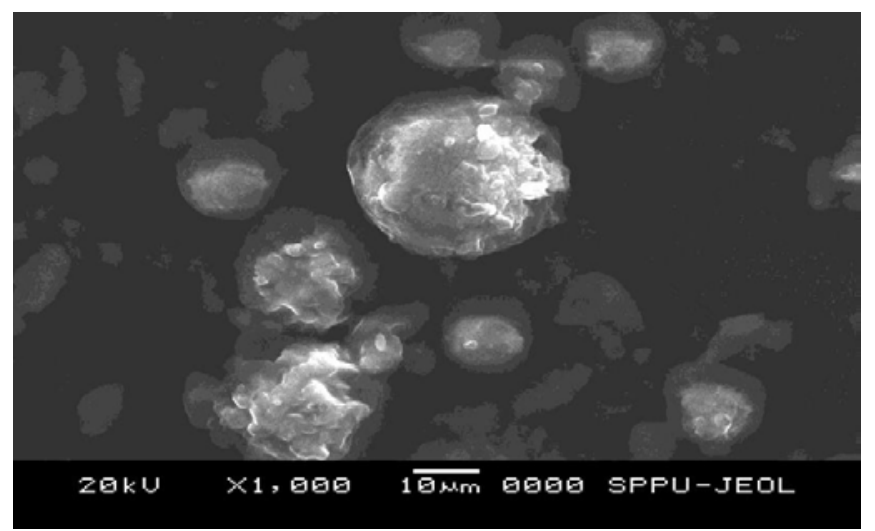

Fig. 7: Surface morphology of optimized formulation

\section{SEM study}

Surface morphology (fig. 7) of optimized formulation was performed by using SEM. The study showed an almost spherical shape of the microsphere and having a porous nature.

\section{DISCUSSION}

DSC of pure drug sample showed a sharp endothermic peak at $85{ }^{\circ} \mathrm{C}$ which was near to its melting point range $\left(72-74{ }^{\circ} \mathrm{C}\right)$. The nature of the peak showed the purity of the drug sample. The FTIR of pure 
drug and mixture with xanthan showed all peak ranges are uniform. DSC and FTIR study showed that drug and excipients are compatible with each other.

The mathematical models generated employing regression analysis and ANOVA were found to be valid, as the observed values for the response parameters 1)\% Entrapment efficiency increases by increasing amount of glutaraldehyde and lowering the stirring speed, 2)\% cumulative drug release increases by increasing concentration of glutaraldehyde and decreasing the stirring speed and also 3)\% Mucoadhesion increases by increasing concentration and lowering stirring speed of the optimized formulations were in close agreement with the predicted values. This study also showed the response surface plot for all the responses. These studies showed that the experimental $\mathrm{P}$ values are less than 0.005 hence, showed the significance of the model for all the responses.

The formulation F2 showed the highest bioadhesive strength $(90.22$ $\%$ after $1 \mathrm{~h}$ ), $96.43 \%$ drug release at $6 \mathrm{~h}$, and $67.65 \%$ drug entrapment efficiency so selected as optimized formulation. Based on the preliminary study Combination of Chitosan and Xanthan shows good results hence selected for further study. Microspheres prepared by using guar gum-gt-acrylamide showed low entrapment efficiency(56.9 \pm 1.5$)$ So, as per the above result using xanthan gum was better than guar gum-gt-acrylamide [18]. Optimized formulation F2 showed higher entrapment efficiency (67.42 \pm 1.032 ).

The in vitro release data were subjected to the curve fitting analysis to know the complex mechanism behind the drug release, the drug release data to the Korsmeyers-Peppas model and the Higuchi model indicating that the drug release mechanisms from these microspheres were diffusion release. The stability study showed that there were no major changes made on microspheres. SEM study showed a porous spherical microsphere formulation.

\section{CONCLUSION}

The study revealed that the development of mucoadhesive microsphere.22 factorial designs was prepared and evaluated to study composition and processing factors. Regression analysis was carried out to obtain the regression coefficient effect as stirring speed and concentration of glutaraldehyde factor found to be significant for reponse $1 \%$ EE, $2 \%$ cumulative drug release and $3 \%$ mucoadhesion. The above result conveys that the amount of glutaraldehyde and stirring speed plays an important role in the formulation of the mucoadhesive microsphere. Based on the results of the dissolution profile, \% Mucoadhesion and \% Entrapment efficiency and good stability study. Factorial batch F2 was found to be optimized.

\section{AKNOWLEGEMENT}

The authors are grateful to the SGRS College of Pharmacy, Saswad for providing research facilities.

\section{FUNDING}

Nil

\section{AUTHORS CONTRIBUTIONS}

All the authors have contributed equally.

\section{CONFLICTS OF INTERESTS}

Declare none

\section{REFERENCES}

1. Shailesh L, Mahesh K. Controlled release approach to novel multiparticulate drug delivery system. Int J Pharm Pharm Sci 2012;4:757-63.

2. Dey NS, Majumdar S. Multiparticulates drug delivery system for controlled release. Trop J Pharm Res 2008;7:1067-75.

3. Ravindra B, Yogesh Y, Nilesh P, Jaiprakash V, Potdar B. Bioadhesive multiparticulate (Microsphere) drug delivery system. J Drug Delivery Ther 2013;3:176-85.

4. Vikram K Sahu, Nitin Sharma, Pratap K Sahu. Shushing a saraf formulation and evaluation of floating-mucoadhesive microspheres of novel natural polysaccharide for site-specific delivery of ranitidine hydrochloride. Int J Appl Pharm 2017;9:15-9.

5. Hemlata K, Harikumar L, Amanpreet K. Mucoadhesive microsphere as the carrier in drug delivery: a review. Int J Drug Dev Res 2012;4:21-3.

6. Indian Pharmacopoeia, Government of India, Ministry of health and family welfare. Vol. 1. Published by the controller of publication, The Indian Pharmacopoeia commission Ghaziabad; 2014. p. 2633-5.

7. Martin G, Berry D, Brown B. Preparation and evaluation of the in vitro drug release properties and mucoadhesion of novel microsphere of hyaluronic acid and chitosan. JCR 2000;6:281-92.

8. Tank K. Development of a new analytical method for quantitative estimation of racecadotril as an active pharmaceutical ingredient by UV spectrophotometer. Int J Pharm Sci Res 2012;3:1495-7.

9. Raymond C, Paul J, Sian C. Owen 6th edition, Handbook of Pharmaceutical Excipients. Published by the Pharmaceutical Press 2009;314:564-74.

10. Sellappan V, Ali A. Formulation and evaluation of ritonavir mucoadhesive microspheres. J Chem Pharm Res 2014;6:952-60.

11. Pawan C, Sanjay S, Anil B, Akanksha G. Bioadhesive microsphere: a review. World J Pharm Res 2015;4:2277-7105.

12. Sandeep K, Nanda A. Formulation, optimization and in vitro evaluation of the gastroretentive mucoadhesive microsphere of furosemide. Int J Pharm Pharm Sci 2016;8:392-8.

13. Nirav P, Dhagesh A, Praful D, Vikram P. Microsphere as novel drug delivery. Int J Pharm Life Sci 2011;2:992-7.

14. Sarrita T, Anna B, Jaswanth A. Design and evaluation of forskolin buccal mucoadhesive microsphere. Int J Curr Pharm Res 2015;7:17-21.

15. Jadhav S, Sharma Y. Mucoadhesive microsphere. Indo Am J Pharm Res 2015;5:2231-6876.

16. Navneet V, Pronobesh C. In vitro and in vivo evaluation of mucoadhesive patches containing metoprolol succinates. Asian J Pharm Clin Res 2014;7:47-52.

17. Pawan C, Sanjay S, Anil B, Akanksha G. Bioadhesive microsphere: a review. World J Pharm Res 2015;4:2277-7105.

18. E Chandra Sekhar, KSV Krishna Rao, R Ramesh Raju. Chitosan/guar gum-g-acrylamide semi IPN microspheres for controlled release studies of 5-Fluorouracil. J Appl Pharm Sci 2011;1:199-204. 